DOSSIER: DIGITAL PATHS: BODIES, DESIRES, VISIBILITIES

\title{
Self-exposed nudity on the net: \\ Displacements of obscenity and beauty?*
}

\author{
Paula Sibilia**
}

\section{Resumo}

This article focuses on images of nude female bodies that circulate today within the media, and on the internet in particular. Prime attention is given to the images that women publish as self portraits. From a genealogical perspective, we examine the politicization involved in a new set of practices, diverse but recent, and how they impact on current redefinitions of beauty standards and criteria defining what is considered to be obscene.

Palavras-chave: Body, Subjectivity, Nudity, Obscenity, Internet.

* Received January 31, 2015, approved March 24, 2015. Translated by Miriam Adelman. Reviewed by Richard Miskolci.

** Professor in the Graduate Program in Communication (PPGCOM) and the Department of Media and Cultural Studies of the UFF, Niteroi, Rio de Janeiro, Brazil.sibilia@ig.com.br 
Over the last few decades, the boundaries around what kinds of images can be legitimately shown in public have been redrawn, particularly where sexuality and women's naked bodies are concerned (Sibilia, 2008). Increasingly distant from the typical $19^{\text {th }}$ and $20^{\text {th }}$ centuries forms of modesty and including fields that range from advertising and video clips to the visual and performing arts and the self-portraits that multiply through the social networks of the web, showing naked bodies seems to be the latest fashion. Furthermore, a wide range of women are taking up a certain kind of activism spurred by the younger generations, exhibiting their nudity in the name of a multiplicity of "noble" causes, whether ecology, reproductive rights, freedom of expression or respect for cultural difference. Famous actresses and models, as well as many "anonymous" women who post their selfies on the internet and organized collectivities such as Femen, Slutwalk, Free the Nipple and World Naked Bike Ride are a part of this trend.

As of the beginning of the 21st century, both the numbers and variety of this new wave of activists has not ceased to expand. For example, the California-born group Baring Witness has been carrying out activities throughout the world over the last decade. Its core project is the photographic documentation of pacifist messages "written" with naked bodies strewn on the ground in patterns that forms phrases meant to be read out loud. "It is no accident that Baring Witness began with women", comments its founder, Donna Sheehan. In addition to an alleged common concern over violence, the text on the group's website explains that "It is no accident either that women would choose to get naked for the sake of peace and justice". From this perspective, then, the question is to make use of "the greatest weapon women have, the power of the feminine, the power of our beauty and nakedness to awaken our male leaders and stop them in their tracks". ${ }^{1}$

1 Baring Witness, http://www.baringwitness.org. 
This connection between a new type of protest and femininity has also been emphasized by historian Philip CarrGomm (2010:89). "While the history of nakedness in religion is dominated by menthe reverse situation applies in the realm of political action, where nakedness has been used most frequently by women". An exemplary case that he uses as evidence for his argument is that of the 40 Indian women who, in 2004, marched naked through the streets of a city of that Asian nation to protest a rape and murder committed by soldiers. Although the protest was successful in attracting media attention, few newspapers published photos of the demonstration, perhaps because "they could not stomach the thought of showing middle-class Indian women (read 'mothers') naked". He cites a local source that points to paradox: "and this in a country where virtually every newspaper has a scantily dressed woman poised in a corner of the front page, disturbingly close to the masthead" (Carr-Gomm, 2010:97).

This attitude seems to imply that there are several kinds of nudity, or at least not just one. Thus we should ask whether this distinction is a novelty or not: is it a contemporary invention or did we inherit it from older traditions? This is a central issue for what is to be examined in this article, wagering on the potential of a genealogical vision to study this currently pertinent question. In this vein, perhaps we could say that the human figure "has always been the object of art, par excellence", as Henry-Pierre Jeudy (2002:13) has suggested. Yet going beyond mere continuity, we consider the significant transformations of the representations that run through the history of Western artistic expression and have at their core the idealized nude that appears in an infinite number of paintings and sculptures. Such images were present even in times in which strict moral precepts would have severely condemned the exposure of flesh and blood human bodies in these very same public spaces. Yet "real" bodies - conveniently dressed - did not hesitate to admire and revere the idealized ones that were, in fact, monumentally exhibited. 
This apparent inconsistency can be explained using a number of different types of argument, or at least, attempts to do so have been made. According to Kenneth Clark's renowned theory, for example, classical nudity was "nude" rather than "naked", a subtle but critical difference that the English language allows. In canonical Western art, a clear distinction is made between these two types of nakedness. The artistic nude, conventionally associated with beauty - a sort of chaste veil capable of covering up the disgraceful - was exempted from the discomfort emanating from crudely, simply naked bodies and their shamefully open way of revealing the uncovered body (Clark, 1987:17).

Moving in a similar direction, although coming from a different perspective and with other interests in mind, comes Giorgio Agamben's illuminating essay, Nudity (Nuditá). In Christian tradition, when Adam and Eve enact the original sin, "the parts of the body that in glory land (glorianda) could be freely exposed, become something to be hidden (pudenda)" (Agabem, 2011:100). Our persistent Christian heritage thus insists on the enormous difference between someone who is nude seen as comparable to the innocence that prevailed prior to the fall from Paradise, or the sweetness of childhood nudity in its happy lack of self-consciousness - and someone who is naked (whose clothing has been removed, therefore fully conscious of lack, in both literal and metaphoric senses). Thus Agamben's first category may be seen to correspond to Clark's aforementioned nude, and the second to his notion of the naked.

\section{Stripping in public: the new nude}

Dichotomies such as those that place nude and naked in opposition to one another provide the basis for what nudity and the revealing of the body come to mean in our culture. They also permeate the arts and in turn, flow from them, flourishing well into the period in which the secularization of the world is fully underway. It is also for this reason that they may serve as a key 
to understanding changes that are currently taking place in this arena, especially as we witness the emergence of a set of initiatives that seem to contest their insistent legacy, inaugurating the "politicization of nudity" examined here. From such episodes, which have been multiplying over the last decade and have provided us several of the examples given here, public exhibition of nudity, and particularly women's nudity, seems to constitute a media tactic at the service of a number of different interests. All however seem to be consorting in their attempts to politicize a problem. Perhaps most surprising in the diverse manifestations of this new phenomenon is the way more traditional beliefs and values about nudity are not only exploited but taken advantage of, in order to move toward the goals that have been set. At the same time, such values are challenged in previously unheard of ways.

What exactly is this politicization of nudity, and how does it operate? In exposing themselves outside the boundaries of the private sphere, whether in the public space of the streets or within media showcasing, these nude bodies cause a certain commotion and attract the gaze of many strangers. This is how they win the visibility sought after, over the wide spectrum of causes they defend. Yet this is only possible because such acts bring together two apparently contradictory tendencies. On the one hand, the fact that nudity is not what it used to be greatly widens the boundaries of what can be shown and what can be observed. Thus, many women are willing to take their clothes off publicly and can do so without significant risks, contrary to the considerable moral and juridical pressure what would have been at stake several decades ago. On the other hand, in spite of the relaxing of taboo and law, nudity continues to stir anxieties, and this itself is enough to turn these new practices into efficient means for attracting attention and thereby consummating their political role.

Nonetheless, as these new practices proliferate with insistence and speed, it is likely that they will come to be taken as ordinary and thereby lose their effectiveness as media spectacle. 
For the time being, however, their tactics seem to function, galvanizing curiosity and public interest. At present, the issue recently raised by the French newspaper Le monde is still valid: "For many, their message is more visible than audible". In other words, nudity is so attractive that it calls everyone's attention, even those who should be concentrating on the noble causes behind the protests, often eclipsed by the instigating images they project. "Could it be that the public sees something beyond the breasts?", asks one of the specialists consulted for the news report, making specific reference to the Ukrainian group Femen. "Have authorities really reacted to these protests?", continues the query. $^{2}$

These are pertinent questions that need to be explored with care. Nonetheless, what we want to emphasize here is something more basic: these issues take off from the premise that the sight of nude female bodies retains a certain potential to scandalize contemporary spectators, even in an era that is thoroughly saturated with images of bodies and ever more sexually permissive. Thus, it is important to look into how old moralities and new forms of politicization are operating. How do accusations of obscenity (the naked) and imposed ideals of beauty (the nude) interact, as two different currents running through a dense Western tradition emerging around the female nude? In the reactions of today's public, do older qualms springing from Victorian morality persist, thereby infusing these gestures with more intense political content? Although such arguments are frequently heard and may be somewhat convincing, there are other indications to the contrary, in the light of significant changes in the meaning of nudity that characterize the passage from the $20^{\text {th }}$ to $21^{\text {st }}$ centuries. This posits the need for a genealogical gaze, the only way in which the nuances of the process can be fully captured.

2 "Est-ce que le public y voit autre chose que des seins?", Le Monde, Paris, 22/02/2012. 
To come to grips with the questions on the horizon and the scope of changes at stake, it is worthwhile remembering that in the year 1955, one of the first women who dared to appear on an Argentine beach wearing a bikini was violently obliged to vacate the scene, under accusations of obscenity. ${ }^{3}$ Two decades later when the libertarian movements of the 1960s were almost a part of the past -, Brazilian actress Leila Diniz caused legendary uproar by exposing her pregnant belly on the sandy beaches of Rio de Janeiro. Yet today, going topless and even nudism itself are allowed on public beaches around the world, including urban parks in major cities such as Berlin and Barcelona. The images of nude or semi-nude female bodies have become a trivial sight within contemporary visual fields, not only because "celebrities" show off their nude bodies in advertising campaigns, news reports and video clips but also because "ordinary folk" lend themselves to phenomena such as amateur porn and post sexy selfies on the internet.

An example of this trivialization of public nudity can be found in the publicity campaign "Come half-naked, leave fully dressed", which the Catalonian designer Desigual has been conducting since 2010 in several cities around the world. To this date, over 12,000 people have taken part in the event, which involves standing in line in front of their stores for hours, dressed only in underwear, in order to get into the store and try on endof-the-season sale items and take two pieces home for free. ${ }^{4}$ Over the last two years, participants have had to get fully undressed, a novelty that has not undermined the initiative's success. Other similar events have also gathered huge crowds in diverse locations across the planet. Most certainly, this can be seen as astute commercial appropriation of a new terrain which in this new century has been skillfully taken advantage of for political protest purposes, taking on a wide variety of uses and expressions. The artist Spencer Tunick is another such example,

\footnotetext{
3 "La bikini cumple hoy 50 años". Viva, Buenos Aires, 07/1996.

4 "Entre desnudo, salga vestido". El Mundo, Madri, 8/1/2014.
} 
having successfully engaged thousands of volunteers in his work: since 1994, he has photographed dozens of "human art installations" in which massive groups of people pose nude in dramatic landscapes around the world.

Yet, if nudity has become undeniably ordinary, many of the old forms of modesty tied to bourgeois morality and its Christian legacy fallen by the wayside after the 1960-1970 revolts, we are left with a new doubt: what is the political value of today's "sexy activism" that is both historically unique and typical now in the early $21^{\text {st }}$ century? How and to what extent does this activism "work"? These are some of the issues underlying this article, begun with an awareness that there are many ingredients to the debate, some of which are mutually contradictory.

One noteworthy case is helpfully revealing of all the complexity at stake. "What woman has never imagined herself on the cover of a men's magazine?" is the question posed on the website of a company called Nude, devoted to producing "sensuous essays of ordinary women". They answer their own question by clarifying that "this is exactly what Nude Magazine has to offer, following the standards set up by the most respected publications on the market." 5 In Brazil, this type of service became popular as a result of the soap opera, Viver a vida, exhibited by the TV Globo broadcasting company in 2009, whose plot included photographic productions of this sort, specifically for older women. "It became common for women to ask for more sensual photos to give to their boyfriends as gifts", explained the woman responsible for the agency in this sector which is said to have inspired the television character: "we came to the conclusion that ALL women would like to see themselves in sensuous poses. It's good for their ego and self-esteem". ${ }^{6}$

Nonetheless, emphasis should be given to the fact that, although celebrated in certain environments, not all analysts wax enthusiasm for this overflow of pornographic aesthetics within

\footnotetext{
${ }^{5}$ Nude, http://www.nude.art.br.

6 "Sensualidade ao alcance de todas". Photo Channel, 8/08/2012.
} 
contemporary visual fields. Art historian Lynda Nead, for example, author of a classic text on the matter, denounced women's fixation on such an "objectifying" genre of Western tradition, the female nude, a legacy that she sees as being reproduced in productions such as those we have mentioned above. Feminist scholar Nead is also a furious critic of traditional theories of the type discussed earlier in this text. Her central argument is that such theories also subscribe to the nude's objectification of silhouettes, whether valued for representing an ideal, as in Kenneth Clark's case (1987), or rejecting the latter for similar reasons and eulogizing, in its place, the depiction of "the naked" and its singular carnal realism, as British author John Berger (1999) recently advocated. In Nead's version of feminist critique, these different positions may appear to be opposites, yet in fact converge in the way both of them work to de-activate certain bodily potentialities.

Yet in spite of such condemnations of the new bodily signs and forms emerging in the wake of the 1960s and 70s, more and more women seem to be choosing to expose their nude bodies on the screens of the world. Nowadays this often includes going beyond their traditional role as models who pose for male artists and spectators. It is no coincidence that media showcases in which it is possible to expose oneself are also on the rise and that access to them is so rapidly multiplying. Aesthetic variety therein is equally abundant: they may emulate and update classical nudes or contest them through the strength of a new and generalized naked. Yet there is another ingredient in the contemporary phenomenon that should be emphasized: the boundaries between both categories are blurring. In this sense, that which Frances Borzello (2012) refers to as "naked nude" has emerged. Art historian Borzello, also coming from a feminist perspective, notes that in a variety of contemporary manifestations we see the two previously exclusive forms coming together, joined within a contemporary regime of visibility that is perhaps a way of struggling against the persistent dichotomies 
which, within certain present-day contexts, may be considered conservative.

A symptomatic example of these transformations as they move beyond the strictly artistic sphere and spill over into the field of media in the broad sense of the term is the case of Jackie Chamoun, a Lebanese skier who was chastized by authorities in her country in 2014 after appearing semi-naked in video that "leaked" onto the internet. It was actually the "making of" of some photographic shots that were taken three years earlier, and had not been disseminated until she took part in the Sochi Winter Olympics.

As a protest against this attitude of censorship, hundreds of people published their own nude photos on Facebook, holding signs with the phrase "I'm not nude, I'm taking my clothes off for Jackie. $^{7}$ This reaction, which unfolded via internet, was comparable to what happened when the Tunisian Amina Tyler published a topless photo of herself on her Facebook page, with the following inscription, written in Arabic, on her torso: "my body belongs to me and is not the source of anyone's honor". The episode took place in 2013 and triggered the participation of women from all over the world, who also bared their breasts in photos posted on the web, with the words "Free Amina" written on their flesh. A similar protest campaign took place in Brazil, in 2014, under the slogan "I don't deserve to be raped", also using the internet as a vehicle. ${ }^{8}$

Some two years earlier, the Chinese artist Ai Weiwei had faced charges in his country for appearing nude next to four naked women. It was not long before dozens of other people did similar shots of themselves which they also spread via internet, with the caption "nudity is not pornography". ${ }^{9}$ In 2012 , images of

\footnotetext{
7 "Fuerte apoyo en Facebook para la atleta libanesa filmada en topless", Clarín, $13 / 02 / 14$.

8 "Nem elas nem ninguém merece...", Época, 04/04/2014.

9 "Ai Weiwei fans post nude photos in response to pornography investigation". Washington Post, 21/11/2011.
} 
an undressed Prince Harry of England were captured by paparazzi who shot them in a private party and later published the images in a magazine. This triggered a reaction in which thousands of sympathizers spread their own photos on the internet in which they appear in varying degrees of nudity, lending their support to the British queen's grandson. ${ }^{10}$ All these recent cases raise an issue which is intimately related to the basic concerns of this article: how can someone be questioned about appearing nude in public and soon have a multitude of strangers defending him or her by taking off their own clothes and making their images available via internet?

This previously unheard of phenomenon converges with other manifestations of the contemporary nude examined here and contributes to the density of moralization and politicization issues, suggesting complex dislocations in the way obscenity is defined. In particular, there has been a certain relaxing of the pornographic gaze that is typical of the modern era - a secularized form of judgment that befell images of nude bodies and that accompanied the exhaustion of Christian hegemony, as studied by Sibilia (2014). In short, this type of gaze promoted an eroticizing or medicalizing view that placed itself at a considerable distance from those who were used to seeing the body through a pre-modern or non-Western gaze, and for such reasons may be seen as gravitating around different "regimes of visibility" (Miles, 2008; Sibilia, 2013).

\section{Dislocations and redefinitions in conflict}

In our attempt to capture the meanings of these current changes, a broad and careful mapping of contemporary phenomena is accompanied by genealogical analysis. This methodological arsenal should enable us to confront the changes that have influenced and affected "ways of seeing" and produced transformations in "regimes of visibility", particularly with regard

10 'Naked Salute' To Prince Harry, Huffington Post, 29/08/2012. 
to images of nudity - especially women's - and their connotations regarding the erotic and the obscene. "The nude was sacred, in other words, impure", Paul Valery explained in a famous 1936 text. He then went on to state that such a condition "was allowed in statues, at times with greater reservations" and that "those grave folk who were afraid of it in living bodies admired it in marble". This ambivalence is fundamental, considering that "the nude had never had more than two meanings: it was at times the symbol of Beauty, and others, of Obscenity" (Paul Valéry apud Haddad, 1990). Here another version of the classic opposition mentioned earlier re-emerges: on the one hand, nudity praised in forms that are considered to be pure and beautiful (nude); on the other, the nude body scorned and considered offensive in its naked immodesty.

This same argument is explored by Michele Haddad (1990), who uncovers some of the characteristics of the artistic nude during its heyday: the $19^{\text {th }}$ century. Haddad highlights the always threatened balance between the "divine" (nude) and "impure" (naked) that artists of that period - almost always men - were near obsessive about representing on canvas and in sculpture. She shows how a certain realist impetus began to subvert the idealization of feminine forms, particularly as of 1860, taking the lead from painters such as Gustave Courbet and Édouard Manet through works such as L'origine du monde (1866) and Olympia (1863). Today, a century and a half after such audacity was shown, we see this bellicose realism re-emerging in new tones and, in some ways, encouraging other advances in the politicization of the female nude. Yet in many cases the classic dichotomies seem to persist (divine-nude and impure-naked), although it is precisely against them that many of the initiatives discussed here have been carried out.

Thus, given how widespread these images have become over the last decade, it is now possible to find examples of such tendencies throughout an ample selection of artistic and media manifestations. There are underwear advertisements featuring "plus size" models and cosmetics made for "real women", for 
example, as well as singers and actresses who proudly show off bodies that are "outside the norm", turning this into effective aesthetic and political slogans. Further novelty is to be found in a wide range of projects in the visual and performing arts (photography, painting, art installations, performance and dance) as well as in newspaper reports of all types and even in shining new "amateur porn". In fact, one of the "good causes" defended by bodies that today are anxious to exhibit themselves is precisely everyone's right - more so, any woman's right - to show off her nude body, beyond the private space that early modernity's "civilizing processes" had allocated to them (Elias, 1994; Bologne, 1986; Vigarello, 1996). Yet this "democratization" of female nudity that is so apparently on the rise today continues to run up against at least two of its ancestral enemies: on the one hand, acceptance based on current aesthetic standards (divinenude); and on the other, stigmatization based on notions of what is "obscene" (impure-naked).

There is a long and dense history to this, although it is increasingly clear that its bases are neither eternal nor universal. The insistence that nude bodies can be understood in terms of two polar opposites, in a total and mutually exclusive sense, underlies the basis of what was (and probably continues to be) one of the most important genres of the Western artistic tradition: the nude. This dichotomy makes itself present even in current manifestations that strive to promote its definitive collapse. Among such the initiatives that have come to the forefront in recent times are The nu project and the Beautiful body project, as well as the two Brazilian projects Apartamento 302 and X Real. "Most publications that deal with nudity and women's sensuality represent neither the majority nor reality" claims the site that is home to the latter project." That is why X Real does not advocate retouching, "it goes on, followed by the clarifications of its author, Camila Cornelsen: "I treat color but do not do anything 
to clear up skin, cellulite, stretch marks, scars... nothing at all!" This is posited as the precise "charm of the project". ${ }^{11}$

In some cases, seeking to go further in this search for a renewed and almost militant realism, even the professional photographer is dispensed with: it is women themselves who create and post their own images. Such is the case of Me in my place, for example, where anyone can exhibit herself at home going about daily tasks in the nude or however she desires. A bit hotter are projects like I shot myself or I feel myself, in which artistic ambition and "amateur porn" come together. The former encourages its collaborators to "subvert the paradigm" by taking nude shots "using your creativity to go beyond the stereotyped vulgarity of pornography". The latter show videos of women masturbating, which arealso made available by the protagonists themselves. On Brazilian sites such as Diário da putaria [Disreputable diaries] which can be accessed for free, any woman can exhibit her photos or videos and interact with a commentposting public. The variety of body shapes that are such sites expose are considerable, with a certain abundance of characteristics that do not often show up in common media silhouettes: thinness and muscles are not compulsory, nor are silicone implants or total depilation.

In addition to not lining up with the fit and retouched bodies of current media, many of these initiatives defy convention regarding the age of the women they show. "Porno blogs" are especially interesting given the degree of autonomy they allow, since each woman is able to decide what to show and how to show it, without intermediaries. Many of the authors are between 40 and 50 years of age, are mothers and/or housewives and share images or texts about their sexuality. There is also a frequent defense of what they see as "real and authentic experience" in opposition to a style that is considered "false" both within porn and conventional advertising. Therefore, although a certain formal affinity between the latter and their

\footnotetext{
${ }^{11}$ X Real, http://www.xreal.com.br.
} 
own images can be detected, not only these new protagonists but also many observers argue that what they do is in fact different, if only because it is the women themselves who have chosen to represent their own erotic selves rather than simply accepting a codified performance catering to the other's gaze. For these reasons, this complex and often contradictory phenomenon becomes part of a tendency that is known as the "post pornographic", implying that there has been some interruption of the version of the female nude as constituted by pornographic genres.

Thus, the challenge that these novelties present can be related to the moral and aesthetic conventions underlying the classical female nude in Western art and how they have irradiated through $19^{\text {th }}$ century European culture: canonical notions of beauty and the ambiguous limits of what can be considered obscene seem to be strongly contested by these new genres. Nonetheless, we should avoid reducing the complexity of the phenomenon, since issues of beauty are key on the agenda of many of these initiatives, albeit in entirely new ways.

A report done in 2013 claimed that these projects tend to attract "women with a clear political position, that of asserting the natural beauty of the female body". One of the people who was interviewed on this occasion was the photographer responsible for the site Apartamento 302, Jorge Bispo, who declared: "all I really want is to do some nudes according to what I believe in, but I've heard some reports along those lines from the young ladies who posed [for me]". Pointing to the main motives that lead women to pose nude for his camera, Bispo mentioned both political demands and another factor: "vanity". ${ }^{12}$ In his politically correct version, this word becomes "self-esteem" and seems inextricably linked to the politicization that is at stake.

12 "Projetos de 'nu verdadeiro' atraem mulheres em busca da beleza natural". Folha de São Paulo, 27/5/2013. 
I think that most people are so accustomed to seeing 'the final product' - retouched and photo-shopped versions of photos -, that their notion of what they should see when they look at themselves in the mirror is completely distorted,

commented one of the young women who participated in The nu project. She added, "perhaps if everyone had the chance to be photographed by an artist, we would all be a bit happier with ourselves". ${ }^{13}$

Starting from similar arguments but taking the issue of the visibility of female bodies even further is the case of the Australian nurse Beth Whaanga, who underwent surgery on several parts of her body for tumor removal and then went on to pose nude for a female photographer. The project, entitled Under the red dress, was meant to "share an experience and encourage others to take preventive measures". Whaanga then decided to post these photos on her Facebook page, providing a warning that the images were "challenging" and included toplessness, yet also added that they were not meant to be construed as erotic. She nonetheless received complaints about the alleged inadequacy of exhibiting a nude body covered with scars through a popular social media. As a result, close to 100 "friends" stopped following her and a few even went so far as to report her for censorship. $^{14}$

Reactions of this type suggest that, notwithstanding the growing "democratization" that has been achieved in the struggle for politicization of the naked female body, the desire for realism in nude depictions may have its limits. In fact, rather than promoting the extinction of old moralities, it seems that there is an ongoing process of redefinition of what is to be understood as obscene. It is no longer the exposure of the most hidden parts of anatomy or erotic appeal that disturbs the contemporary

\footnotetext{
${ }^{13}$ The Nu Project, http://www.thenuproject.com/info/testimonials.

14 "Beth Whaanga's powerful breast cancer portraits lost her 100 friends, but could save many more lives", The Huffington Post, 14/2/2014.
} 
spectator's gaze and must thereby be keep "behind the scenes" or out of sight. Rather, increasingly - and perhaps due to a gradual "depornification" of the gaze (Sibilia, 2014) -, censorship tends to focus on other angles: certain aesthetic criteria regarding the shapes and surfaces that are being exhibited. An illustration of these dislocations can be found in another easy example: in this case, a young lady who posed nude for the Apartamento 302 project. She reported that her boyfriend was "shocked" when he found out, but soon got over the initial scare: "it's normal for people today", she declared soon thereafter, and even claimed that her parents "showed the images off in family reunions" and that her children "also think it's great". ${ }^{15}$ Therefore, notwithstanding the important and ongoing questions that are presently being raised, it does not seem like concerns about beauty and obscenity have fallen by the wayside. Rather, they are being reformulated in complex and extremely significant ways.

\section{Ambiguities, contradictions and resistance}

As part of this struggle for the right to exhibit real bodies an important aspect of the politicization of nudity we are focusing on here - measures to limit the use of programs such as PhotoShop in editing body images for media exposure have been advocated. One of the arguments that has been made is that manipulated images may be "harmful to one's health", contributing to the proliferation of eating disorders and compulsive plastic surgery, among other things. Thus, undermining the philosophical reservations that pretentions of "being faithful to reality" have brought out in other arenas, one of the initiatives that is being taken has been to formulate laws that require a warning be published to accompany images that have been altered, as well as imposing high fines on those who do not comply with new rules and regulations. France is a

15 "Sem roupa, com atitude". Revista O Globo, Rio de Janeiro, 1/9/2013, p. 32. 
pioneer in this regard, approving a law of this type in the year 2009. "When writers take a real event and embellish it, they are obliged to let their readers know that it is fiction or dramatization of real facts", argued the congresswoman who proposed the bill, concluding, "Why should photography be any different?". ${ }^{16}$

Two more examples can be given here, in the interest of a clearer understanding of the scope of the problems we are looking at here, and bringing us closer to drawing some conclusions. One of them refers to the 2011 case of Mexicana Airlines flight attendants whom, having lost their jobs when the company closed down, posed in Playboy magazine to draw attention to their plight. ${ }^{17}$ In itself, this is hardly exceptional, as media tactics such as these have become increasingly common. What is surprising, however, is that shortly thereafter, an original shot of the essay was spread via internet, without the postproduction work and thus revealing the excessive digital touch up of the final image that went to press. ${ }^{18}$ The polemic therefore was not only widened but also dislocated: the fact that the women had undressed publicly was no longer the issue, but moralizing complaints were insidiously directed toward the lack of authenticity in the bodily images thus revealed. Most impressive was a certain poorly disguised sarcasm that people manifested regarding the women's lack of adequacy to current aesthetic standards. It was this that made the image "obscene" in the eyes of contemporary spectators, rather than the unexpected nudity or eroticism implicit in it.

The second episode occurred in the United States in the year 2010, when the National Organization for Women celebrated its annual Love Your Body Day, meant to denounce eating disorders and to reinforce the self-esteem of women whose

\footnotetext{
16 "Ditadura do Photoshop". Veja, 21/10/2009.

17 “Con ligas y poca ropa, pelean por sus derechos: ¿todo vale?”. Entremujeres, Buenos Aires, 7/4/2011.

18 "Desilusión en el aire: un reclamo desdibujado por el Photoshop". Entremujeres.
} 
bodies are "outside the norm". For these purposes, the institution hired two plus -sized models to appear nude in their campaign material. This lead to a series of repercussions in the media. When a female journalist asked whether the photo had been edited, she received the explanation from one of the models that it had, "but not size-wise". She recognized that "color correction and other interesting photographic resources" had been used. After arguing that nowadays "all photos are adjusted" she went on to emphasize "but our waistlines were not retouched, nor were our spare tires removed, nor were my breasts reduced". ${ }^{19}$ Nonetheless, the smoothing out of bodily surfaces was considered to be excessive, especially because it seemed inconsistent with the desired underlying message which was to "encourage women of all different sizes to love the skin they are in". ${ }^{20}$

These details, however humdrum they may seem, are important and close to the core of the problem that is examined here. On another occasion, we examined the "rectifying Puritanism" revealed in the use of tools such as PhotoShop (Sibilia, 2012:105). Such tools, which in their brief 25 years of existence have become fundamental to the production of body images, "protect women from becoming truly naked insofar as they eliminate bodily imperfection", according to Brazilian anthropologist Mirian Goldenberg (2008:81). She adds that their usage is equivalent to "putting clothing on women, as their wrinkles, stretch marks, cellulitis and spots are removed". With this modest task, digital polishing creates the skin anew, "completely smooth and immaculate." This image purification, widely naturalized within the contemporary regime of visibility, should not be belittled in our analysis of the way obscenity is dislocated and nudity is politicized in the contemporary world. On the contrary, it is a morally significant issue, since it ends up

\footnotetext{
19 "The Naked Photo Everyone's Talking About". iVillage, 25/08/2010.

20 "Size 10 model Whitney Thompson on loving her body", Examiner, 13/09/2010.
} 
creating a situation in which the only body "that even without clothing is decently dressed", according to current values, is the one that is "fit, cared for, has no undesirable marks (wrinkles, stretch marks, cellulitis, spots) and no excess (fat, loose flesh)" (Goldenberg, 2002:29).

This recognition at least partially counters the political demands for the cheerful and authentic "undressing" that is currently in vogue. In fact, such beliefs seem to be an updated version of the traditional idea of the artistic nude - or, to be more exact, the nude that is morally tolerated, in opposition to a more carnal and realistic naked that continues to be disturbing. This in turn serves to sustain the 19th century distinction between the divine and the impure, albeit reformulated and acquiring other meanings that become more efficient within the contemporary context. It is no longer the same as the definition of obscenity that was embraced by "bourgeois morality", denoting the impurity of the naked, now that age old taboos have been weakened by the "sexual liberation" movements of the $20^{\text {th }}$ century. Yet, in order to have access to the increasingly desired nude, it is still necessary to be divine. As Brazilian actress Maria Ribeiro declared in a 2014 report, summarizing what is at the heart of the dislocations we have examined here: "my paranoia regarding nudity came from modesty; today, it is about being a looker". ${ }^{21}$

In short, and not withstanding all the battles that rage today, it seems that the scenario that has come to be after all the readjustments brought about by the revolts of the 1960s and 1970s has been left standing, as so perceptively summarized by Michel Foucault (1979:147) in an interview he gave in 1975: "Stay nude... as long as you are thin, handsome and tan". The irony that was fitting at that moment in history remains alive in the ambivalence of current attitudes toward self-exposure in female nudity, at political and moral levels. Such ambiguities have deep

21 "Minha paranóia da nudez era o pudor, hoje é a de estar gata". O Globo, $13 / 12 / 2014$. 
roots in our culture, although they have been transformed by historical changes and movements that have led to today's unexpected outcomes. They hark back to Christianity's complex fusion of Judaism's prohibitions and Greco-Roman worship of certain bodily practices and images, transporting us to the Renaissance, when classical ideals were brought back to life. The fuller consequences of these processes took shape through $19^{\text {th }}$ century bourgeois modesty, ushering in the hypocritical taxonomy of the divine and the impure, a categorization that complements the Victorian opposition between nude and naked.

Thus, it seems that the contemporary gaze continues to enforce a dichotomous distinction, one that is moral and political, separating media's polite silhouettes from the polluted ones that are struggling for their rights, as in the examples we have provided above. However, our intention here has been to detect certain ongoing transformations and dislocations in which both bodies and the observing gazes that, in one single act both judge and invent them, have undergone considerable change. The genealogical perspective adopted here focuses on certain historical factors that participate in these processes of change, imprinting their particularities on a contemporary phenomenon. In all their complexity, they are fruit not only of the heritage of certain important traditions that mark our culture, but also of the struggles and gains of the last few decades, that include both the popularization of interactive medias and the intense moral and legal reformulations that are underway at present.

\section{Some final considerations}

In sum, we are dealing here with a very fervent social and cultural battlefield. The efficacy of strategies of the media and artistic self-exposure that we have brought into focus, if only with regard to their basic goal of attracting attention, is contingent upon a certain moralization that continues to infuse contemporary gazes. If the potentially scandalous meaning of female nudity and the attempts at censorship that it so often 
provokes had been more completely eroded, such practices would be little noticed. Yet within the current scenario, it seems to be undergoing significant mutation, and this is the sole reason that the novel practices we have examined here appear. On the one hand, resulting from the relaxation of many age-old moral taboos, it has become more viable for any woman to expose her nudity in public spaces. Yet on the other hand, the criteria that provided support for the notions of the female nude that prevailed within Western tradition up until the Modern Era have not been extinguished - albeit some changes in the way obscenity is defined and certain reformulation of beauty standards are quite apparent.

The complexities referred to above gave birth to a Brazilian event that was baptized as Toplessaço (something along the lines of 'Let's all go topless!'), organized through the social network, Facebook for December 21st, 2013, on Ipanema beach, right at urban heart of Rio de Janeiro immortalized in the famous bossanova song of the 1960s about the girl who is "tall and tan and young and lovely". Thousands of people joined the call that was spread via internet, committing themselves to participate in this day of partial, mass undressing in which Brazilian women would defend their rights to go around topless on the beaches of the country. Yet at the time the event was to take place, the locale was invaded by journalists, photographers and by the curious in general - mobilized by their own "pornifying" gaze, inhibiting the women and largely annulling the political potency of the demonstration. ${ }^{22}$ Thus, the diverse values that are at stake in this complex phenomenon of the politicization of female nudity gathered that day on the Rio de Janeiro beaches. Beauty, obscenity, spectacle, shame, freedom, purity, humiliation, censorship, pornification, and even a promised and never completely consummated de-pornification of the gaze were present, materializing in the confused forces that today confront

22 "Toplessaço atrai mais curiosos do que seios descobertos no Rio", G1, 21/12/2013. 
one another on this variegated battlefield. In January of 2015, another attempt was made to gather people under the same banners at the very same beach. All the problems that had appeared on the previous occasion appeared again and in intensified form, including the gesture of selecting the "muses" of the event and a greater emphasis in its spectacularization. Yet at the same time, some critique went on, pushing in the direction of a possible "de-pornifying" of the gaze, and the polemics that were stirred up then continue on the agenda of the day. In January of 2015 another attempt was made on the same Rio de Janeiro beach, under similar banners. ${ }^{23}$

In order to draw some conclusions, it is important to emphasize that all this is occurring within a very particular historical context, in which media have become a fundamental factor - and in particular, graphic and audiovisual means of communication and most recently, the interactive social networks that operate within digital networks - exercising an ever-more powerful influence on individual lives and over dynamics of sociability. This stimulus contributes, in ways that are both vigorous and complex, to the shaping of bodily and subjective configurations. It has become habitual, for example, to define the contemporary era as one in which the "cult of the body" has become an original element of social life. This tendency has in recent decades spread over all the cultures that are joined through global media and markets and is quite strong in Latin America, and in Brazil in particular. It implies certain changes in the way embodied subjectivities are experienced. On the one hand, the body becomes an "object of cult", playing an increasingly preeminent role within a civilization that traditionally pushed it off to one side, yet now inspires all possible forms of care, devotion to health, fitness and shape. On the other hand, the human body has also been extremely constrained by a series of beliefs and values that seem to hold the conditions of the flesh

${ }^{23}$ Toplessaço: escolha de musas gera polêmica, BBC Brasil, 18/1/2015. 
in contempt, expressed through the stubborn mystifications of beauty, health, thinness and youth.

At the vortex of this multiple and contradictory excitation, the contemporary body is both adored and laboriously sculpted as an image that should be kept smooth and polished. At the same time, and for the same reasons, it is rejected in its organic materiality, and must constantly be subjected to numerous procedures of bodily purging and purification. The role that communications media play within these processes is primordial and played out through a tacit alliance with the market and with techno-science, since the incessant irradiation of media images and discourse contribute to the dissemination of hegemonic body standards and publicize an ever-expanding catalog of techniques, products and services that should enable people to attain them. Along with the latter comes a long list of the physical and moral risks that inhere to feared inadequacies. A certain morality that advocates "being in shape" has clearly taken over, occupying spaces that had been freed from older demands such as those imposed by disciplinary norms, and a type of entrepreneurship of the self is called upon, for the successful management of one's own "body capital". There are several different vectors that feed into this apparent paradox around the status of the human body in the contemporary era, simultaneously the object of cult through idealized and highly codified images - and of scorn, insofar as is consists of the fleshy materiality that is the basis of all vital experience.

For these reasons, it seems, a large portion of the images of the female body that are disseminated through contemporary mass media - including many of those that originate in selfexposure - belong to the idealized vision of the divine or polished nude. That is, they reproduce the very representations against which the most forceful artistic impetus of modernity initially expressed itself, in a now distant time, and today still proposes to denounce or subvert, attempting to move beyond the old dichotomy that poses as its opposite that which is naked and therefore impure and polluted. Although dismantled and much 
debated, this classic opposition is nonetheless constantly returned to. One of those who has done so most recently in art historian Arthur Danto, in his attempt to explain a certain discomfort linked to the strong effects of bodily presence in Lucian Freud's portraits. The bodies painted by this British artist seem to be truly naked, rather than nude, in the awe-provoking sense of today's flat screens - whether tvs, computers, tablets or smartphones and on the glossy pages of magazines. These venerated bodies, in turn, "dress nudity as if were clothing when they take the latter off, exchanging one suit for another" (Danto, 2003:69), alluding to the photo of a model who in her nudity seems to be fully dressed".

Within this context, denaturalizing these truths through genealogical tools becomes a complicated endeavor. At the same time, given the considerable relevance of the body in contemporary culture and the subtlety of the tethers of image that have been deployed by the new devices of power, it has become all the more urgent. The purifying gaze that today promotes the censorship of body images - particularly of female nudity, and all the more so when they are the product of self-exposure responds to new moral rules, quite different from those that "subjected" human bodies throughout the disciplinary era, although hardly less severe and certainly causing equallydamaging effects. What we have sought to do in this article represents an initial attempt to understand what this transformation means. It no longer seems to be the sight of nude bodies or brazen sexuality that disturbs current values, as was the case under the spell of the modern era's pornifying gaze. Rather, bodily exposure is often stimulated at present, with one reservation: the silhouettes represented must be smooth, fit and shapely. This is the tricky "morality of being in shape" that sustains and stirs today's "cult of the body": it is not always identified as a moralizing injunction, and often appears as just one more option among the many that depend on the way people exercise free choice and are limited to the aesthetic sphere. 
Nonetheless, some of the movements that we have examined here suggest considerable resistance to such processes, despite their complexities and ambiguities. In short, certain contemporary artistic and media manifestations - in which this "naked nude" is represented as one more current of politicization - aim at a critique of astute current mechanisms of subjugation, in an attempt to reactivate certain vital forces that seem to be dormant or repressed, thereby seeking to invent new modes of dealing with the nudity of self and other. In their quest, we get a glimpse of a possible de-pornification of the gaze, as a promise of important changes that could affect the current regime of visibility. It is an opening which, heading toward new and currently unimaginable horizons, might be able to revert the tendency that was initiated in the early modern era: the pornification of a gaze that has poured over nude silhouettes ever since the "disenchantment of the world" - and the subsequent sexualization and medicalization of body images that came along with secularization processes.

These initiatives - so current, so diverse, so recent and active - seem to include among their objectives the implosion of forms of codifying bodies which stubbornly renew old idealizations of the 19th century artistic nude under the spotlights of today's media, in ways more compatible with the globalized culture of the $21^{\text {st }}$ century. In this sense, new strategies emerge, contesting in different ways the more naturalized images and discourses in a visceral "anger at the mirror", as suggested by Pierre Jeudy. Or through a rejection of the screens and showcases that impose themselves from everywhere, indefatigably capturing and projecting these silhouettes that have been purged of all their fleshy vitality. Thus, perhaps in the new proposals we focus on here "the body, as an infinite power of the possible" attempts to demonstrate that this angry exposure "has no need to subject itself to the rules of the spectacle" (Jeudy, 2002:110). It is in this sense that such efforts may be seen as novel responses to Foucault's witty (and conditional) 1975 invocation to "stay nude". In this regard, the cases we have 
examined here may be seen as more or less desperate attempts to politicize the problem, seeking to invent utterly new forms of living our embodied conditions and to subverting old dichotomies, which in their current versions are all the more effective and all the harder to avoid.

\section{Bibliography}

Agamben, Giorgio. Desnudez. Buenos Aires, Adriana Hidalgo, 2011.

BERGER, John. Modos de ver. Rio de Janeiro, Rocco, 1999.

Bologne, Jean Claude. História do pudor. Lisbon, Teorema, 1990.

Borzello, Frances. The naked nude. London, Thames \& Hudson, 2012.

CARR-Gomm. A brief history of nakedness. Londons, Reaktion Books, 2010.

ClARK, Kenneth. El desnudo. Madrid, Alianza, 2006.

DANTO, Arthur. La madonna del futuro. Barcelona, Paidós, 2003.

ElIAS, Norbert. O processo civilizador. Rio de Janeiro, Jorge Zahar Editor, 1994.

Foucault, Michel. Poder-Corpo. In: Microfísica do poder. Rio de Janeiro, Graal, 1979, pp.145-152.

GoldenBERG, Mirian. Coroas. Rio de Janeiro, Record, 2008.

. (org.) Nu \& Vestido. Rio de Janeiro, Record, 2002.

HADDAD, Michele. La divine et l'impure: Le nu au XIXe. Paris, Jaguar, 1990.

JEUDY, Henry-Pierre. O corpo como objeto de arte. São Paulo, Estação Liberdade, 2002.

MILES, Margareth. A complex delight: The secularization of the breast, 1350-1750. Berkeley, University of California Press, 2008.

NEAD, Lynda. El desnudo femenino. Madrid, Tecnos, 1998.

SiBILIA, Paula. O show do eu: A intimidade como espetáculo. Rio de Janeiro, Ed. Nova Fronteira, 2008. 
198 Self-exposed nudity on the net

O corpo velho como uma imagem com falhas. Comunicação, Mídia e Consumo, ano 9, vol. 9, n 26, São Paulo/ESPM, nov. 2012, pp.83-114.

- Os corpos visíveis na contemporaneidade: Da purificação midiática à explicitação artística. In: BRASIL, André; LISSOVSKY, Maurício; MORETTIN, Eduardo. (orgs.) Visualidades hoje. Brasília/Salvador, Compós/EDUFBA, 2013, pp.119-136.

. O que é obsceno na nudez? Entre a Virgem medieval $e$ as silhuetas contemporâneas. FAMECOS, vol. 21, n 1, PUC-RS, 2014, pp.24-55.

VIGARELLO, Georges. O limpo e o sujo: Uma história da higiene corporal. São Paulo, Martins Fontes, 1996. 